\title{
IMPACT EVALUATION OF R\&D SUPPORT FOR SMES AND START-UPS AND ITS FEEDBACK ON PROJECT MANAGEMENT
}

\section{MASAKI UEYAMA, MOTOSHI KUNUGI, TOSHIYUKI ISSHIKI, SHUMPEI MIYAJIMA AND SHIN UESAKA} DOI: 10.22163/fteval.2019.335

\section{INTRODUCTION}

\section{ABOUT NEDO}

$\mathrm{F}$ Tollowing the two oil crises of the 1970s, the need for energy diversification increased. Against this backdrop, the New Energy Development Organization was established as a governmental organization in 1980 to promote the development and introduction of new energy technologies.

Research and development of industrial technology was added in 1988, and today New Energy and Industrial Technology Development Organization (NEDO) plays an important part in Japan's economic and industrial policies as one of the largest public research and development management organizations with an annual budget for FY2018 of 159.6 billion yen (1.23 billion euro). It has two basic missions: addressing energy and global environmental problems, and enhancing industrial technology.

Drawing on its considerable management know-how, NEDO carries out projects to explore future technology seeds as well as mid- to longterm projects that form the basis of industrial development. It also supports research related to practical application.

\section{EVALUATION SYSTEM IN NEDO}

NEDO has established and been applying its own evaluation system for nearly two decades. Figure 1 shows the overall scheme of present NEDO evaluation and monitoring, at various stage of a 5-year project. Starting from the project planning stage, we have a set of four evaluation chances for each project.

1. Ex-ante evaluation, that is performed when it is still at the planning stage, to see how the project is worth being carried out. The results of an ex-ante evaluation are fed back for refining the project plan and requesting the final budget scheme.

2. Mid-term evaluation, that is performed typically once for a project, and the results are directly reflected to the management of the project for the rest of the period.

3. Just after the project is finished, an ex-post evaluation is performed. The results of ex-post evaluation are often used as a reference to planning of a related new project. For each midterm and ex-post evaluation, an external subcommittee of typically 7 members, is organized.
4. In addition to these 3-step evaluation series, NEDO conducts follow-up monitoring in every other year for 6 years. Follow-up monitoring is done by NEDO evaluation department, supervised by an external specific subcommittee, using questionnaire and interview method. This survey is necessary for the impact evaluation, which assesses the post-project development by the participant companies, and the resulting impact of the project to the society.

Follow-up monitoring directly determines the present status of the project ranked as a 5-level TRL-like stage; 1) still under elementary research, 2) technology development, 3) already practically applied, 4) successfully commercialized, or 5) unfortunately terminated (abandoned). By applying this to all NEDO Projects, the success rate (expected probability of success) of NEDO projects will be estimated. The detail of follow-up monitoring is also described in the next section.

The overall results of ex-post and impact evaluation of all NEDO projects are then used for the accountability for tax payers, and for improving the project management system in general.

Figure 1. Overview of NEDO project evaluation

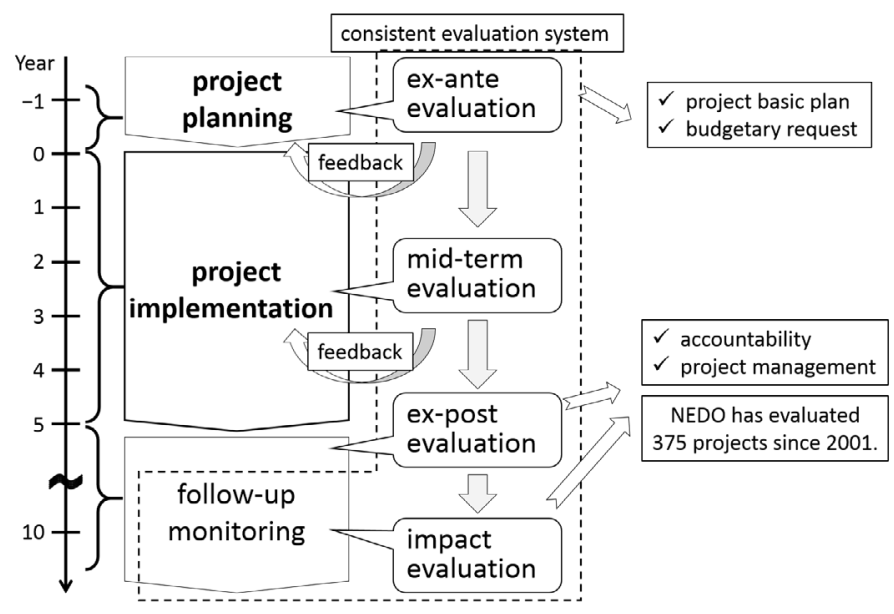




\section{EXTENDED FOLLOW-UP SURVEY}

In 2009, we started an additional "extended follow-up survey" for selected NEDO projects that successfully created new innovative outputs products or processes - utilizing core technologies that are developed by the project. We name these outputs "NEDO-inside products" (Yamashita et al. 2013), and a total number of 115 are registered at present. The extended follow-up survey is continued even after the end of the first 6 -year monitoring period, and the data are used for estimating key indicators such as sales, return on investment and societal benefits by each product. Combining the results of follow-up monitoring and extended follow-up survey enables us to assess and disseminate the economic and societal impacts of NEDO R\&D impacts, and then to reflect the knowledge in the improvement of project policy and management through success / failure factor analysis.

\section{NEDO'S SUPPORT FOR SMES INCLUDING START-UPS}

In recent years, NEDO is focusing not only in promoting large-scale national projects based on national roadmaps, but also in supporting RGD of "small- and medium-sized enterprises ("SMEs" hereafter) including start-ups. The definition of SMEs and start-ups is shown in the next section.

This relatively new strategy of NEDO is set due to the fact that, in general, (1) faster development is expected by SMEs than by large companies, (2) innovation is liable to occur in so-called niche areas, where large companies dare not intend to do, and (3) societal impacts such as indirect economic effects may appear more directly on SMEs than on large companies. Some recent research (Farja, Y., Gimmon, E., Greenberg, Z. (2017), Foreman-Peck, (2013), Radas, S., Anic, I-D., Tafro, A., Wagner, V. (2015)) done in various countries shows, in general, that funding via subsidies is more effective and efficient for supporting innovations by SMEs than other measures such as tax incentives. From this viewpoint, a series of NEDO funding scheme have been reorganized to seamlessly support SMEs according to their present R\&D phase (feasibility study, fundamental, development etc.).

Because the average size of R\&D activities of SMEs is relatively small compared to that of large companies, the impact of their R\&D onto the whole society is unlikely to show up clearly. On the contrary, as for the impact on the SMEs themselves, it is expected that the R\&D results will have a greater impact on the growth and survival of the company itself, than in the case of large companies.

In this study, we used the data from follow-up monitoring and extended follow-up survey and analyzed three aspects as follows.

1. Commercialization rate

2. Success / Failure factors

3. Effects on the participating SMEs

\section{COMMERCIALIZATION RATE}

SMEs (including start-ups) are defined, under the Small and Medium-sized Enterprise Basic Act of Japan (1963), as private sectors that fulfil either condition of the following.

Table 1. Definition of SMEs.

\begin{tabular}{|l|l|}
\hline Capital Stock & Number of employees \\
\hline Not more than 300million yen* & Not more than 300 \\
\hline
\end{tabular}

*approximately 2.3 million euro

There is no universally quantitative definition of "start-up companies", and in this study we conveniently set a start-up as an SME which is less than ten years old.

First, we checked the commercialization rate ("success rate") of SMEs using our follow-up monitoring data, and saw if it is significantly different from that of total commercialization rate of all NEDO projects including large companies.

Follow-up monitoring is done for all organizations that participated in NEDO projects (ca. 800 / year), at 1/2/4/6 years after the termination of each project. Web-based questionnaires set for the monitoring consists of four parts:

I. Present status of the post-project activities- using status of R\&D subject ranked as a 5-level stage (TRL-like) defined above.

II. Possible factors of success or failure (Why success / failure?)

III. How was the project management provided by NEDO?

IV. Objective of participating in the project (process improvement, new business etc.)

The answers to these questionnaires are used not only for estimating the overall success rate of a certain group of projects (projects with SMEs in this case), but also to ensure accountability of the funding policy, to improve NEDO's project management and to assess social impact of the projects.

We analyzed 837 NEDO projects in which SMEs participated by applying the above mentioned viewpoints, using the data of follow-up monitoring and extended follow-up surveys. If the present status of the post-project activities falls into either 3) practical application or 4) commercialized of the 5-level stage, it is counted as a "success".

Table 2. Success rate of SMEs.

\begin{tabular}{|l|c|c|c|}
\hline Category & $\begin{array}{l}\text { The number of } \\
\text { projects } \\
\text { (The number of } \\
\text { companies) }\end{array}$ & $\begin{array}{l}\text { The number of } \\
\text { successful projects } \\
\text { (The number of } \\
\text { successful } \\
\text { companies) }\end{array}$ & Success rate \\
\hline SMEs excl. start-ups & $445(351)$ & $150(132)$ & $33.7 \%$ \\
\hline Start-ups & $392(293)$ & $129(114)$ & $32.9 \%$ \\
\hline Total SMEs & $837(644)$ & $279(246)$ & $33.3 \%$ \\
\hline
\end{tabular}

Our overall results in Table 2 showed, SMEs achieve a practical application rate of around $33 \%$, which is remarkably higher than the average value of $25 \%$ for all NEDO projects including those done by large companies. This result is consistent with other research for SMEs in other 
region of the world (Office of Extramural Research, National Institutes of Health, (2009); SQW Ltd. (2015)).

\section{SUCCESS/FAILURE FACTOR ANALYSIS}

As an extended follow-up survey for this study, we conducted a series of individual interviews for 30 chosen SMEs that reached "success" stage with excellent results. Our preceding research (Kunugi et al. 2016) revealed some key factors leading to discontinuing / resuming projects, and further accumulation of data was utilized to analyse SMEs in this study.

The interview in this study consists of four parts:

I. Status of R\&D results, practical application and commercialization

II. Specific activities taken by the company to achieve the results

III. Whether the company had enough resources to proceed those activities effectively

IV. Actions taken to complement resource deficit / to make good use of present resource

The entire set of interview answers are analyzed by extracting common tendencies and differences between companies. We found four tendencies summarised below.

a. Thorough ex-ante knowledge on the business environment and the strengths of the company: target customers, market/ technology region

b. Securing the resources: from both inside and outside of the company, including effective sharing of the resources

c. Adjustment by judging the change of the environment: continuous survey and search for the output market

d. Continuous effort for resources: resources are continuously needed after reaching practical application stage, for manufacturing and sales activities

\section{EFFECTS OF PROJECTS ON THE PARTICIPATING SMES BY DID ANALYSIS}

In order to obtain a reliable estimate of the effect of NEDO projects on participating SMEs, it is not enough to analyze only data for the companies who did participate the project, as this would not eliminate the external effects such as macroscopic economic trends on the results.

A Difference-in-differences (DID) analysis was also conducted in this study accordingly. Recent reports of DID analysis applied to the evaluation (Foreman-Peck, (2013), Ministry of Economic Development, New Zealand, (2011)) shows its reliability compared to traditional methods such as case studies, which tend to overestimate the additionality measurement.

In the DID analysis, a group of companies that participated in NEDO projects ("the NEDO group") and a group of companies that did not participate ("the control group") but similar to the NEDO group in terms of other attributes (e.g. sales, number of employees, type of business and region) were selected and examined. Details of the method we adopted in this study are described in Inoue, H. and Yamaguchi, E. (2017).

Figure 2: Schematic diagram of the DID analysis.

\section{DID analysis}

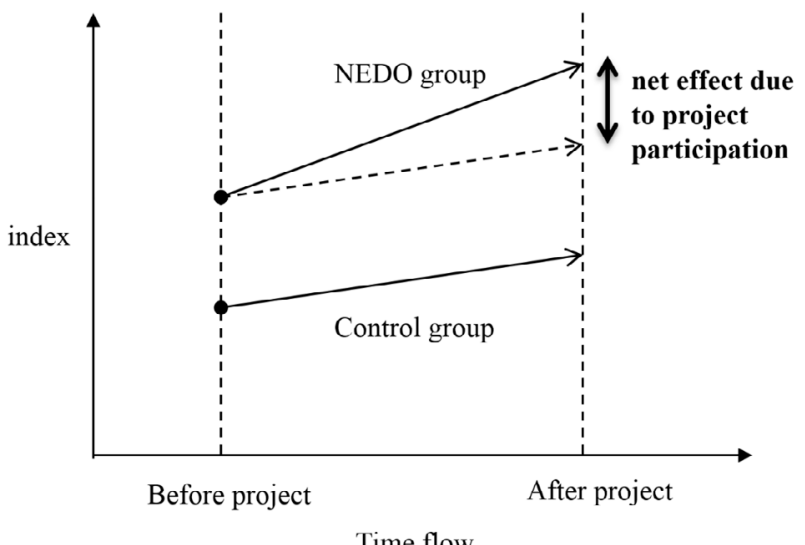

The population of our DID analysis comprises two groups: "NEDO group" that started a NEDO project between years 2007 and 2010, and the control group. Each company in the control group set is chosen for a corresponding "NEDO group" company, by comparing the location, type of industry, sales amount and number of employees.

Out of 442 "NEDO group" original companies, we found control companies and used the pair for the analysis.

The change in "performance indicators" such as sales amount and number of employees within six years - from the year each project begins and six years after that - was estimated for each company, and was then compared for the NEDO group and corresponding control group.

Average sales of each group for both year 0 and year 6 and their growth rate is shown in Table 3 and 4, respectively.

Table 3. Average sales amount of each group (million yen).

\begin{tabular}{|c|c|c|c|}
\hline $\begin{array}{c}\text { NEDO group } \\
\text { year 0 }\end{array}$ & $\begin{array}{c}\text { NED0 group } \\
\text { year 6 }\end{array}$ & $\begin{array}{c}\text { Control group } \\
\text { year 0 }\end{array}$ & $\begin{array}{c}\text { Control group } \\
\text { year 6 }\end{array}$ \\
\hline 2,688 & 2,956 & 2,502 & 2,573 \\
\hline
\end{tabular}

Table 4. Average sales increase rate of each group.

\begin{tabular}{|l|c|c|}
\hline & NED0 group & Control group \\
\hline $\begin{array}{l}\text { Average sales increase } \\
\text { between year 0 and 6 }\end{array}$ & $48 \%$ & $12 \%$ \\
\hline
\end{tabular}

From these results, the increase of sales looks larger for NEDO group than control group. We then tested these results statistically.

The Shapiro-Wilk test of the distribution of sales and the growth rate showed are both not on normal distributions. The Mann-Whitney's $\mathrm{U}$ test, which is a non-parametric method used for group comparison, showed significant differences at the significance rate of $5 \%$.

Similar analysis on the number of employees did not show a significant difference at the significance rate of $5 \%$. 


\section{CONCLUSIONS}

In recent years, NEDO is focusing not only on promoting large-scale national projects based on national roadmaps, but also on RGD support for SMEs including start-ups. In this study, the impact evaluation of NEDO's R\&D support for SMEs and start-ups is investigated using NEDO's "follow-up monitoring" and "extended follow-up survey" data for all project participants.

The average "success" rate for SMEs was around 33\% for both startups and SMEs excluding start-ups, which was significantly higher than the rate of large companies participating in NEDO projects, which was around $25 \%$.

Further series of individual interviews for 30 chosen SMEs that reached "success" stage with excellent results, sales increase for example, were conducted to identify common tendencies as keys to success. As a result, business environment around the expected products together with resource securing were found to be particularly important, both in the planning stage of the R\&D, and the continuous period after the application stage.

A DID analysis was also conducted to clarify the effect of NEDO projects on participating SMEs, eliminating the external noise such as macroscopic economic trends. Careful choosing of DID controlled group and statistical tests revealed a difference on the average sales growth rate.

\section{REFERENCES}

Farja, Y., Gimmon, E. and Greenberg, Z. (2017). The developing in the developed: Rural SME growth in Israel, The International journal of entrepreneurship and innovation, 18, 36-46.

Foreman-Peck, J. (2013). Effectiveness and efficiency of SME innovation policy, J., Small Business Economics, vol.41 no.1, 55-70.

Inoue, H. and Yamaguchi, E. (2017). Evaluation of the Small Business Innovation Research Program in Japan, SAGE Open, 2017:1-9. DOI: $10.1177 / 2158244017690791$.

Kunugi, M., Ueyama, M., Isshiki, T. and Tokuoka, A. (2016). Follow-up Survey on Discontinued R\&D Activities, session 1774, Evaluation 2016, American Evaluation Association, Atlanta, Georgia USA.

Ministry of Economic Development, New Zealand, (2011). Evaluation of the Impacts of Cross-Vote Government Assistance on Form Performance.

Office of Extramural Research, National Institutes of Health, (2009). National Survey to Evaluate the NIH SBIR Program -Final Report.

Radas, S., Anic, I-D., Tafro, A. and Wagner, V. (2015). The effects of public support schemes on small and medium enterprises, Technovation, $38,15-30$.

SoW Ltd. (2015). Evaluation of Smart; Impact and Process Evaluation.
Yamashita, M., Yurugi, Y., Shishido, S., Yoshida, T. and Takeshita, M. (2013). Impact evaluation of Japanese public investment to overcome market failure review of the top 50 NEDO Inside Products, Research Evaluation 1-21.

\section{AUTHORS}

MASAKI UEYAMA

E: ueyamamsk@nedo.go.jp

MOTOSHI KUNUGI

E: kunugimts@nedo.go.jp

TOSHIYUKI ISSHIKI

E: isshikitsy@nedo.go.jp

SHUMPEI MIYAJIMA

E: miyajimaspi01@nedo.go.jp

\section{SHIN UESAKA}

E: uesakasin@nedo.go.jp

Evaluation Department, New Energy and Industrial Technology Development Organization,

1310 Omiya-cho, Saiwai-ku, Kawasaki City, Kanagawa 212-8554 (Japan) 